International Journal of Linguistics, Literature and Culture
Available online at https://sloap.org/journals/index.php/ijllc/
Vol. 7, No. 6, November 2021, pages: 506-510
$\begin{aligned} & \text { ISSN: 2455-8028 } \\ & \text { https://doi.org/10.21744/ijllc.v7n6.1977 }\end{aligned}$

\title{
Empathy as an Expression of Emotions and Mood in English Lingvoculture
}

Gulnoza I. Narmurodova ${ }^{\text {a }}$

Article history:

Submitted: 27 September 2021

Revised: 18 October 2021

Accepted: 09 November 2021

\section{Keywords:}

compassion;

culture;

emotion;

empathy;

expression;

mentality;

synonyms sympathy;

\section{Corresponding author:}

Gulnoza I. Narmurodova,

Senior Lecturer, Department of General Linguistics, Uzbek State World Languages University, Tashkent, Uzbekistan.

Email address: g.ilhomovna@gmail.com

\begin{abstract}
This article provides information on the expression of feelings in expressing sympathy in English culture. There are a lot of emotions. The way they are expressed is special and unique for each culture and is influenced by various historical, social, and cultural factors. Therefore, as there are people in the world, there are as many ways to express sympathy. Each person chooses for himself how to express joy, sorrow, compassion, or simply remain silent and stay on the sidelines. The study of the verbal expression of sympathy allows us to assert that a sympathetic attitude can induce a person to the following speech actions - the expression of sympathy or condolences. Various factors influence the choice of a specific speech act. Emotions such as sympathy and condolence are aimed at establishing speech contact and maintaining speech and social relations with the interlocutor, at regulating them.
\end{abstract}

International journal of linguistics, literature and culture (C) 2021. This is an open access article under the CC BY-NC-ND license (https://creativecommons.org/licenses/by-nc-nd/4.0/).

${ }^{a}$ Senior Lecturer, Department of General Linguistics, Uzbek State World Languages University, Tashkent, Uzbekistan 


\section{Introduction}

Each person has special character traits. Therefore, as there are people in the world, there are as many ways to express sympathy. Each person chooses for himself how to express joy, sorrow, compassion, or simply remain silent and stay on the sidelines. Now we need to define the word "sympathy". It is worth mentioning that there are a huge number of definitions that have certain semantic differences. Let's start with the definition given by Ushakov's explanatory dictionary: "Compassion is compassion for the grief and misfortune of a stranger". Empathy is understood by I. B. Levontivoy as a feeling that a person experiences when he thinks that someone is bad, and accepts this pain as his grief. Empathy is a feeling of compassion or understanding that allows a person to interpret or justify the actions and feelings of another. In the first meaning, there is a clear connotation of feeling together with others, and in the second meaning closer to the feeling of another person (Stubbs, 1983; Gennadievna et al., 2018).

\section{Materials and Methods}

The definition used can thus lead to real confusion. Difficulties arise from the tendency of English speakers to use the term in the first meaning, and French speakers, where there is a word with a common origin, to use it in the second meaning. In various psychological works and 17 scientific literature usually uses the first meaning. In literary criticism, the second meaning is more common (Shakhovsky, 2009; Sergeeva, 2004; Prokopenko, 2016; Hewitt, 1996). Empathy means seeing the other person's problem as your own. This is a positive trait when a person understands the emotions of other people while realizing that these are not his emotions and experiences. We can assume that empathy begins with the ability of a person to listen and delve into other people's problems, and this is what allows you to establish contacts and connections. Many people don't know how to listen, which means they don't know how to empathize. They are busier with their problems and satisfaction of their needs and therefore pay little attention to the experience of others or remain completely indifferent to the problems of others. According to Shakhovskiy (2009), "Empathy is a connecting mass that can transform a group of people into a single whole, thereby ensuring their success at work". Part of the English mentality, as noted, is English politeness. So the ability to express your feelings is an important element in the process of communication in English (Borzenko, 2019; Kovtun, 2016). In more detail, we will consider expressions of such emotions as sympathy and a kind of sympathy, condolences. The most common and typical way of expressing sympathy are statements that were formed a long time ago and are in the form of well-established phrases:

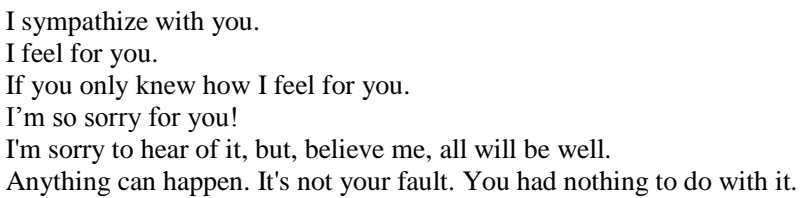

Condolence, as a rule, is appropriate to use only as an expression of sympathy for great misfortune, grief. Most often, condolences are stylistically and emotionally more colored, used only in a formal setting or in writing:

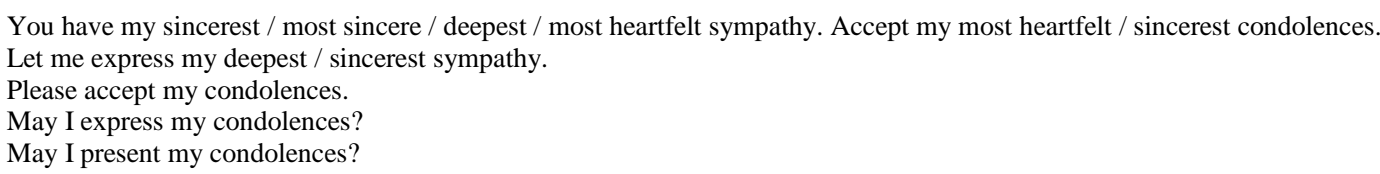

As we know, for the English people etiquette is very important. Since English politeness is an important and integral part of their culture and mentality, it follows that the ability to express empathy is an important element of communication in English. The word sympathy refers to the sphere of corporate communication, and its main purpose is to express understanding and a benevolent attitude towards the addressee in a negative situation for him (MacBeth \& Gumley, 2012; Glăveanu, 2010).

This is also emphasized in the English-language interpretations of the concept expressed by the synonyms sympathy and compassion.

Narmurodova, G. I. (2021). Empathy as an expression of emotions and mood in English lingvoculture. International Journal of Linguistics, Literature and Culture, 7(6), 506-510. https://doi.org/10.21744/ijllc.v7n6.1977 
1) Sympathy sensitivity and understanding of the sufferings of other people are often expressed in a willingness to give help. Sensitivity and understanding of the suffering of others are often expressed in a willingness to help.

2) Sympathy - an expression of understanding and care for someone else's suffering Expression of understanding and attention to the suffering of another.

3) Compassion - sympathy for the sufferings of others, causing a desire to help them. Empathy for the suffering of others and a desire to help them.

4) Compassion - a strong feeling of sympathy and sadness for the suffering or bad luck of others and a desire to help them. Deep sympathy and sadness for the suffering or failure of others and a desire to help them (Gilbert, 2019; Hofmann et al., 2011).

Condolence is stylistically more emotionally charged than sympathy and is used most often in a formal setting, orally or in writing. Condolence is a kind of empathy, but it has its specifics of expression and use that are different from the use of empathy (Thompson et al., 2019; Lorié et al., 2017). As a rule, condolence is appropriate to use only as an expression of sympathy for great misfortune, grief. In a ritual situation, condolences are more stereotypical and stereotyped. Condolence has certain characteristics, it is appropriate for several days after death and, therefore, loses its relevance several months or years after the sad event. Considering the practical foundations of expressing empathy in English communicative discourse, several conclusions have been drawn. Empathy and condolence are used in human speech as a reaction to negative situations. Condolence is a kind of empathy and has its characteristics. Situations of using condolence are different from situations in which empathy is used (Freedberg \& Gallese, 2007; Singer \& Klimecki, 2014).

All situations in which a sympathetic reaction was encountered can be divided into two groups. The first group includes situations that do not depend on a person and are caused by external circumstances. The second group includes situations in the occurrence of which the person himself is to blame. The specificity of English culture is the love of the British for animals. We learned that people show sympathy and condolences not only to people but also to animals. It also became known as tradition, and custom was reflected in the expression of sympathy in the English language. We know that tea is a traditional English drink. They find tea to be soothing and nurturing and warm. This is reflected in English idioms (Besel \& Yuille, 2010; Lamm et al., 2019). There is an idiom associated with expressing sympathy "tea and sympathy". We also found that the most common word for expressing sympathy in the English language is the word "sorry ". And also very often, especially in the press, no special words are used to express sympathy. The author constructs the narrative in such a way that it becomes clear to the reader from the context. Condolence is used only as an expression of sympathy for great misfortune or grief. Condolences are the most stereotypical and stereotyped characters. Also, condolence has certain characteristics: it is appropriate for several days after death and, therefore, loses its significance a few days after the event. The condolences we have analyzed can be divided into two types, which correspond to two types of communication (Pant \& Yadav, 2016; Krisnanda \& Surya, 2019).

\section{Conclusion}

The study of the verbal expression of sympathy allows us to assert that a sympathetic attitude can induce a person to the following speech actions - the expression of sympathy or condolences. Various factors influence the choice of a specific speech act. Emotions such as sympathy and condolence are aimed at establishing speech contact and maintaining speech and social relations with the interlocutor, at regulating them. An important task of empathy in colloquial speech is to play the role of a means of maintaining the conversation. For sympathy, the most important thing is the self-expression of the addressee, for condolence - the fulfillment of a social act.

\section{Conflict of interest statement}

The author declared that he have no competing interest.

Statement of authorship

The author has a responsibility for the conception and design of the study. The author has approved the final article. 
Acknowledgments

I am grateful to two anonymous reviewers for their valuable comments on the earlier version of this paper. 


\section{References}

Besel, L. D., \& Yuille, J. C. (2010). Individual differences in empathy: The role of facial expression recognition. Personality and individual differences, 49(2), 107-112. https://doi.org/10.1016/j.paid.2010.03.013

Borzenko, O. (2019). Increasing The Level Of Speech Culture Of The Foreign Language Teacher. Sustainable development under the conditions of European integration. Part II, 63.

Freedberg, D., \& Gallese, V. (2007). Motion, emotion and empathy in esthetic experience. Trends in cognitive sciences, 11(5), 197-203. https://doi.org/10.1016/j.tics.2007.02.003

Gennadievna, OT, Aleksandrovna, KA, \& Andreevich, BS (2018). Expressing of national and cultural identity in English and Russian proverbs. Bulletin of the Peoples' Friendship University of Russia. Series: Theory of language. Semiotics. Semantics, 9 (2).

Gilbert, P. (2019). Explorations into the nature and function of compassion. Current opinion in psychology, 28, 108114. https://doi.org/10.1016/j.copsyc.2018.12.002

Glăveanu, V. P. (2010). Paradigms in the study of creativity: Introducing the perspective of cultural psychology. New ideas in psychology, 28(1), 79-93. https://doi.org/10.1016/j.newideapsych.2009.07.007

Hewitt, K. (1996). Understanding Britain. Perspective Publications.

Hofmann, S. G., Grossman, P., \& Hinton, D. E. (2011). Loving-kindness and compassion meditation: Potential for psychological interventions. Clinical psychology review, 31(7), 1126-1132. https://doi.org/10.1016/j.cpr.2011.07.003

Kovtun, O. A. (2016). The problem of formation of communicative culture of individual in terms of computerization of society. Інформаційні технології в освіті, (1), 192-209.

Krisnanda, P. H., \& Surya, I. B. K. (2019). Effect of emotional and spiritual intelligence on transformational leadership and impact on employee performance. International Research Journal of Management, IT and Social Sciences, 6(3), 70-82. https://doi.org/10.21744/irjmis.v6n3.634

Lamm, C., Rütgen, M., \& Wagner, I. C. (2019). Imaging empathy and prosocial emotions. Neuroscience letters, 693, 49-53. https://doi.org/10.1016/j.neulet.2017.06.054

Lorié, Á., Reinero, D. A., Phillips, M., Zhang, L., \& Riess, H. (2017). Culture and nonverbal expressions of empathy in clinical settings: A systematic review. Patient education and counseling, 100(3), 411-424. https://doi.org/10.1016/j.pec.2016.09.018

MacBeth, A., \& Gumley, A. (2012). Exploring compassion: A meta-analysis of the association between selfcompassion and psychopathology. Clinical psychology review, 32(6), 545-552. https://doi.org/10.1016/j.cpr.2012.06.003

Pant, I., \& Yadav, R. K. (2016). Impact of emotional intelligence on the job performance of employee. International Research Journal of Management, IT and Social Sciences,3(1), 7-14. Retrieved from https://sloap.org/journals/index.php/irjmis/article/view/342

Prokopenko, V.V. (2016). The verbal expression of empathy in English communicative discourse.

Sergeeva, A. V. (2008). Russians: behavioral stereotypes, traditions, mentality. M.: Flinta: Science.

Shakhovsky, V.I. (2009). Categorization of emotions in the lexical-semantic system of the language. URSS.

Singer, T., \& Klimecki, O. M. (2014). Empathy and compassion. Current Biology, 24(18), R875-R878. https://doi.org/10.1016/j.cub.2014.06.054

Stubbs, M. (1983). Discourse analysis: The sociolinguistic analysis of natural language (Vol. 4). University of Chicago Press.

Thompson, N. M., Uusberg, A., Gross, J. J., \& Chakrabarti, B. (2019). Empathy and emotion regulation: An integrative account. Progress in brain research, 247, 273-304. https://doi.org/10.1016/bs.pbr.2019.03.024 